\title{
Relationship between the Current Account Balance Ratio and Salary Ratio in Japanese Municipal Hospitals
}

\author{
Nozomu Mandai1 ${ }^{*}$, Mayumi Watanabe ${ }^{1,2,3}$ \\ ${ }^{1}$ Ibaraki Prefectural University of Health Sciences, Ibaraki, Japan \\ ${ }^{2}$ Kansai University of Health Sciences, Osaka, Japan \\ ${ }^{3}$ Faculty of Science and Engineering, Chuo University, Tokyo, Japan \\ Email: ${ }^{\star}$ mandain@ipu.ac.jp
}

How to cite this paper: Mandai, N. and Watanabe, M. (2019) Relationship between the Current Account Balance Ratio and Salary Ratio in Japanese Municipal Hospitals. Health, 11, 1591-1597.

https://doi.org/10.4236/health.2019.1112120

Received: November 27, 2019

Accepted: December 20, 2019

Published: December 23, 2019

Copyright $\odot 2019$ by author(s) and Scientific Research Publishing Inc. This work is licensed under the Creative Commons Attribution International License (CC BY 4.0).

http://creativecommons.org/licenses/by/4.0/

(c) (i) Open Access

\begin{abstract}
Background: While public municipal hospitals in Japan are supported by public financing and are less likely to fail than private hospitals, more than half are in financial deficit. Hospitals running at a deficit may have poorer outcomes and less investment in maintenance of human or physical capital, as well as increased rates of patient adverse events. We sought to clarify the relationship between municipal hospital surpluses or deficits and salary expenditures. Methods: We extracted financial data for 253 general hospitals of 300 beds or more from financial statements for the 2013 fiscal year available in the Yearbook of Public Firms, Edition for Hospital. From these data, we calculated account balance ratios and compared the average value of the ratio of labor to the output (salary ratio) for each group using analysis of variance (ANOVA). Results: The salary ratios of hospitals in the surplus group were significantly lower than the salary ratios of hospitals in the deficit group (55.5\% vs. $49.4 \% ; p<0.001$ ). In the deficit group, there was no difference between the average values of salary ratios among the three-bed count groups (mean salary ratio: $57.2 \%$ vs. $54.4 \%$ vs. $53.0 \%$; ANOVA $p=0.342$ ). In the surplus group, the average value of salary ratios was different among the threebed count groups (mean salary ratio: $53.0 \%$ vs. $48.5 \%$ vs. $47.4 \%$; ANOVA $p=$ 0.012 ). In addition, there was a significant difference in mean value between the 300 -bed group and $\geq 500$ beds group (mean salary ratio: $53.0 \%$ vs. $47.4 \%$; $\mathrm{p}=0.002$ ). Conclusion: This study suggests that maintaining a favorable salary ratio to the current account balance is a useful proxy of fiscal health, and interventions to improve the salary ratio may be effective in improving municipal hospital management. Furthermore, among well-managed municipal hospitals, larger hospital size may confer some advantage in purchasing power.
\end{abstract}




\section{Keywords}

Hospital Finance, Salary Ratio, Public Hospital, Current Account Balance Ratio

\section{Introduction}

Japan's health system implemented universal health insurance coverage in 1961 and is one of the most successful health systems in the world, despite having one of the highest life expectancies and the highest old-age dependency ratio among advanced economies [1]. Hospitals in Japan are categorized as public municipal hospitals, which are established under the Japanese Ministry of Health, Labour and Welfare, and private hospitals, which are administered by corporations and constitute the majority of hospitals in Japan [2]. While public municipal hospitals are supported by public financing and are less likely to fail than private hospitals, more than half are in financial deficit. As of 2013, public municipal hospitals accounted for about $10 \%$ of all hospitals in Japan, and most of these municipal hospitals were operating at a loss, with a net loss of 42.92 billion yen (approximately 429 million U.S. dollars) [3]. In response to the high proportion of municipal hospitals in deficit (72.2\% in 2007), the Japanese Ministry of Internal Affairs and Communications issued public hospital reform guidelines to local municipalities in 2007 requesting that they improve public hospital management as quickly as possible [4]. These guidelines were updated in 2015 and require local governments to develop plans to limit spending and increase revenue at public hospitals; in addition, the guidelines require annual assessment and reporting [3]. The guidelines primarily target hospital administration, with a main objective of reducing deficit and reducing subsidies received from local government [5]. While early targets of the guidelines were not met [5], rates of municipal hospital deficit following issuance of this directive eventually dropped to $54.4 \%$ in 2013 and $63.2 \%$ in 2016 (Table 1) [6].

Despite this modest decrease, the number of public hospitals running at a deficit remains high. At the same time, Japanese society is rapidly aging, placing additional burden on the health system, and the national health system itself has undergone major reforms [7]. In the context of an aging society, an uncertain policy environment, tight government control of the fee-for-service system, [8] [9] and rampant deficits among municipal hospitals, a better understanding of municipal hospital finances is needed to ensure the continuity in high levels of care. Hospitals running at a deficit may have poorer outcomes and lower levels of investment in the maintenance of human or physical capital, [10] as well as increased rates of patient adverse events [11]. However, use of health economics analyses in healthcare decision-making processes in Japan has lagged behind that of other developed countries [12]. 
Table 1. Number and percent of deficit hospitals and surplus hospitals between 2007 and 2016.

\begin{tabular}{ccccccc}
\hline \multirow{2}{*}{ Year } & \multicolumn{2}{c}{ Deficit hospitals } & \multicolumn{2}{c}{ Surplus hospitals } & \multicolumn{2}{c}{ Total } \\
\cline { 2 - 6 } & $\mathrm{N}$ & $\%$ & $\mathrm{~N}$ & $\%$ & $\mathrm{~N}$ & $\%$ \\
\hline 2007 & 688 & 72.2 & 265 & 27.8 & 953 & 100.0 \\
2008 & 661 & 70.9 & 271 & 29.1 & 932 & 100.0 \\
2009 & 545 & 59.9 & 365 & 40.1 & 910 & 100.0 \\
2010 & 417 & 47.7 & 458 & 52.3 & 875 & 100.0 \\
2011 & 410 & 48.1 & 443 & 51.9 & 853 & 100.0 \\
2012 & 430 & 51.6 & 404 & 48.4 & 834 & 100.0 \\
2013 & 458 & 55.4 & 368 & 44.6 & 826 & 100.0 \\
2014 & 456 & 56.7 & 348 & 43.3 & 804 & 100.0 \\
2015 & 475 & 59.0 & 330 & 41.0 & 805 & 100.0 \\
2016 & 496 & 63.2 & 289 & 36.8 & 785 & 100.0 \\
\hline
\end{tabular}

To clarify the relationship between municipal hospital surpluses or deficits and salary expenditures, which are a measure of investment in human capital, we analyzed 2013 financial data of 253 municipal hospitals with 300 beds or more from annual financial reports.

\section{Methods}

We analyzed the relationship between the current account balance ratio and salary ratio in Japanese municipal hospitals using data from the 2007-2016 Annual Statistics of Public Enterprises [(Chihou Kouei-Kigyou Nenkan Byouinhen (in Japanese)] [13]. The dataset includes financial and operational data for $839 \mathrm{mu}-$ nicipal hospitals in Japan in the 2013 fiscal year. There are three categories of municipal hospital in Japan: general hospitals, tuberculosis hospitals, and psychiatric hospitals; we targeted general municipal hospitals with 300 or more beds. After excluding hospitals that were under construction $(n=13)$, those with missing data on current account balance and salary ratio $(n=39)$, tuberculosis hospitals and psychiatric hospitals $(n=31)$, and hospitals with less than 300 beds $(n=503)$, we extracted financial data for 253 general hospitals of 300 beds or more from financial statements for the 2013 fiscal year [13].

From these municipal hospital account balance and salary data, we calculated account balance ratios, including the ratio of current expenses to current income (the current account balance ratio, in percent; [ordinary income/ordinary expenses] $\times 100$ ) and the ratio of labor to output (the salary ratio, in percent; [personnel expenses/medical practice income] $\times 100$ ). We then divided hospitals into a deficit group, in which the ratio of current expense to current income was $100 \%$ or more, and a surplus group, in which the ratio of current expense to current income was less than $100 \%$.

We statistically compared the average value of the ratio of labor to the output (salary ratio) for each group using analysis of variance (ANOVA). The homo- 
geneity of the variances was assessed using the Levene statistic. We also conducted stratified sensitivity analyses by bed count (300 - 399 beds vs. $400-499$ beds vs. $\geq 500$ beds) using Tukey's Honest Significant Difference test. All statistical analyses were performed using the Statistical Package for the Social Sciences (SPSS) version 25.0 (SPSS, Inc., Chicago, IL, USA). Statistical significance was set at $p<0.05$.

\section{Results}

A diagram of the study flow is shown in Figure 1. Analyses were based on data from 253 municipal hospitals. Comparison of mean salary ratio values between the deficit group and the surplus group are presented in Table 2. The salary ratios of hospitals in the surplus group were significantly lower than the salary ratios of hospitals in the deficit group ( $55.5 \%$ vs. $49.4 \%$; $p<0.001)$.

Comparison of mean salary ratio values between the deficit group and the surplus group stratified by bed count are shown in Table 3 . In the deficit group, there was no difference between the average values of salary ratios among the three-bed count groups (mean salary ratio: $57.2 \%$ vs. $54.4 \%$ vs. $53.0 \%$; ANOVA $p=0.342$ ). In the surplus group, the average value of salary ratios was different among the three-bed count groups (mean salary ratio: $53.0 \%$ vs. $48.5 \%$ vs. $47.4 \%$; ANOVA $\mathrm{p}=0.012$ ). In addition, there was a significant difference in mean value between the 300 -bed group and $\geq 500$ beds group (mean salary ratio: $53.0 \%$ vs. $47.4 \% ; p=0.002)$.

\section{Discussion}

Among Japan's municipal hospitals, those with lower salary ratios tended to have favorable account balances. In addition, in the surplus group, we found that salary ratios were lower in hospitals with $\geq 500$ beds. However, no such difference was observed among hospitals running at a deficit.

Other researchers evaluating the possible link between hospital size and fiscal health due to the economy of scale in purchasing did not find a significant impact on bargaining power [3]. This may have been due to the real or perceived lack of incentives to use group purchasing power (i.e., administrators are either unaware of the potential cost savings or do not believe that such savings would materialize) or to the expectation of using the newest available (and thus, more

Municipal hospitals in Japan in 2013 fiscal year $(n=839)$

Excluded

$$
\begin{aligned}
& \begin{array}{l}
\text { - hospitals under construction }(n=13) \\
\text { - missing data on current account balance and salary ratio }(\mathrm{n}=39) \\
\text { - tuberculosis hospitals and psychiatric hospitals }(\mathrm{n}=31) \\
\text { - hospitals with fewer than } 300 \text { beds }(\mathrm{n}=503)
\end{array} \\
& \text { Included municipal hospitals }(\mathrm{n}=253)
\end{aligned}
$$

Figure 1. Study flow chart. 
Table 2. Comparison of mean salary ratio values between deficit group and surplus group.

\begin{tabular}{ccccccccc}
\hline \multirow{2}{*}{ Parameter } & \multicolumn{3}{c}{ Deficit group } & \multicolumn{3}{c}{ Surplus group } & \multirow{2}{*}{-value } \\
\cline { 2 - 7 } & N & Mean & SD & N & Mean & SD & \\
\hline Ratio of labor to output (\%) & 109 & 55.5 & 12.9 & 144 & 49.4 & 9.9 & $<0.0001$ \\
\hline
\end{tabular}

Table 3. Comparison of mean salary ratio values in bed count group by financial situation ratio of labor to output (\%). (a) Bed count group; (b) Specific group difference.

(a)

\begin{tabular}{|c|c|c|c|c|c|c|c|c|c|c|}
\hline & \multicolumn{3}{|c|}{$300 \mathrm{~L}$} & \multicolumn{3}{|c|}{$400 \mathrm{~L}$} & \multicolumn{3}{|c|}{$500+\mathrm{L}$} & \multirow{2}{*}{$\begin{array}{l}\text { ANOVA } \\
p \text {-value }\end{array}$} \\
\hline & $\mathbf{N}$ & Mean & SD & $\mathbf{N}$ & Mean & SD & $\mathbf{N}$ & Mean & SD & \\
\hline Deficit group & 55 & 57.2 & 14.2 & 30 & 54.4 & 14.4 & 24 & 53.0 & 5.4 & 0.342 \\
\hline Surplus group & 43 & 53.0 & 8.3 & 36 & 48.5 & 13.1 & 65 & 47.4 & 8.0 & 0.012 \\
\hline
\end{tabular}

(b)

\begin{tabular}{lcccc}
\hline & $300 \mathrm{~L}$ vs. $400 \mathrm{~L}$ & $\mathbf{4 0 0} \mathrm{L}$ vs. 500+ & $300 \mathrm{~L}$ vs. 500+ & ANOVA $p$-value \\
\hline Deficit group & - & - & - & 0.342 \\
Surplus group & - & - & $300 \mathrm{~L}$ & 0.012 \\
\hline
\end{tabular}

Note: 300 L [300 beds level (300 - 399)], 400 L [400 beds level (400 - 499)], 500+ L [500 and more than 500 beds level $(\geq 500)]$.

costly) drugs in highly advanced medical care. A study of American hospitals found that larger hospitals had greater efficiency, but that smaller hospitals had comparable costs to larger institutions [14].

While scale did not confer a significant economic benefit in purchasing power, the managerial requirements of the hospital reform guidelines were associated with increased bargaining power. Purchasing power may be less modifiable in Japan's national single-payer health system than in more free-market-based systems, [8] but cost efficiency in public municipal hospitals is also closely linked to managerial performance, so improving hospital management is a potential avenue to reducing public hospital deficit [15]. While some other cost containment strategies, such as the prospective payment system, have resulted in only limited improvements in efficiency [16], our finding that salary ratios were lower among hospitals running at a surplus offers support for the benefits of management responsibility, which includes control of salaries and revenue.

Additionally, contrary to previous findings [3], our results also suggest that, at least among solvent hospitals with adequate management, larger size may offer additional benefits in negotiating salaries and in purchasing power. Hospitals in good financial standing may have alternatives for cost savings and quality improvements that are not available to hospitals that lack such financial flexibility [10]. Additional research into the association between hospital size and purchasing power by overall fiscal health is warranted.

The strengths of the present study include use of standardized nationwide data on all public municipal hospitals and stratified analysis by hospital size. While 
previous studies have assessed the relationship between hospital size and bargaining power, to our knowledge, this is the first study to evaluate municipal hospital expenses and revenue by hospital size.

However, some limitations also warrant mention. First, we included only general municipal hospitals, excluding private hospitals as well as public psychiatric hospitals and tuberculosis hospitals. Private hospitals comprise the majority of hospitals in Japan, but data for these hospitals is not collected and reported in the Annual Statistics of Public Enterprises [13]. Specialty municipal hospitals serve different populations and have specific financial concerns that preclude aggregation with municipal hospital data. Second, data for our analysis was collected 6 years ago, in 2013; an analysis of more recent data is forthcoming. Third, we also excluded small hospitals with less than 300 beds, which constituted the majority of municipal hospitals in the dataset (503/839 general hospitals). While this decision allowed us to compare data of the highest-volume hospitals, generalizability of our findings to smaller hospitals is limited. Further research on the fiscal health of these smaller hospitals may provide additional useful information for the management of public hospitals in Japan.

\section{Conclusion}

This study suggests that maintaining a favorable salary ratio to the current account balance is a useful proxy of fiscal health, and interventions to improve the salary ratio may be effective in improving municipal hospital management. Furthermore, our results suggest that, among well-managed municipal hospitals, larger hospital size may confer some advantage in purchasing power.

\section{Acknowledgements}

This article was supported in part by a JSPS KAKEN Grant-in-Aid for Early-Career Scientists (N.M. 19K19359).

\section{Conflicts of Interest}

The authors declare no conflicts of interest regarding the publication of this paper.

\section{References}

[1] Nozaki, M., Kashiwase, K. and Saito, I. (2014) Health Spending in Japan: MacroFiscal Implications and Reform Options. International Monetary Fund, Washington DC. https://doi.org/10.5089/9781498365277.001

[2] Japan Ministry of Health, Labour and Welfare (2013) Annual Health, Labour and Welfare Report, 2012-2013. Tokyo. https://www.mhlw.go.jp/engish/wp/wp-hw7/index.html

[3] Noto, K., Kojo, T. and Innami, I. (2017) Does Scale of Public Hospitals Affect Bargaining Power? Evidence from Japan. International Journal of Health Policy and Management, 6, 695-700. https://doi.org/10.15171/ijhpm.2017.29

[4] Niinuma, S. (2013) Health Governance for a Sustainable Rural Community: A Case 
Study of the Approach to Public Hospital Reform in the Oguni-Town, Yamagata Prefecture. Journal of Rural Planning Association, 32, 72-81. https://doi.org/10.2750/arp.32.72

[5] Kawaguchi, H., Tone, K. and Tsutsui, M. (2014) Estimation of the Efficiency of Japanese Hospitals Using a Dynamic and Network Data Envelopment Analysis Model. Health Care Management Science, 17, 101-112. https://doi.org/10.1007/s10729-013-9248-9

[6] Zhang, X. and Oyama, T. (2016) Investigating the Health Care Delivery System in Japan and Reviewing the Local Public Hospital Reform. Risk Management and Healthcare Policy, 9, 21-32. https://doi.org/10.2147/RMHP.S93285

[7] Sudo, K., Kobayashi, J., Noda, S., Fukuda, Y. and Takahashi, K. (2018) Japan's Healthcare Policy for the Elderly through the Concepts of Self-Help (Ji-Jo), Mutual Aid (Go-Jo), Social Solidarity Care (Kyo-Jo), and Governmental Care (Ko-Jo). BioScience Trends, 12, 7-11. https://doi.org/10.5582/bst.2017.01271

[8] Ikegami, N. and Anderson, G.F. (2012) In Japan, All-Payer Rate Setting under Tight Government Control Has Proved to Be an Effective Approach to Containing Costs. Health Affairs, 31, 1049-1056. https://doi.org/10.1377/hlthaff.2011.1037

[9] Ikegami, N. and Campbell, J.C. (2004) Japan's Health Care System: Containing Costs and Attempting Reform. Health Affairs, 23, 26-36.

https://doi.org/10.1377/hlthaff.23.3.26

[10] Beauvais, B. and Wells, R. (2006) Does Money Really Matter? A Review of the Literature on the Relationships between Healthcare Organization Finances and Quality. Hospital Topics, 84, 20-29. https://doi.org/10.3200/HTPS.84.2.20-29

[11] Encinosa, W.E. and Bernard, D.M. (2005) Hospital Finances and Patient Safety Outcomes. INQUIRY: The Journal of Health Care Organization, Provision, and Financing, 42, 60-72. https://doi.org/10.5034/inquiryjrnl_42.1.60

[12] Ikegami, N., Drummond, M., Fukuhara, S., Nishimura, S., Torrance, G.W. and Schubert, F. (2002) Why Has the Use of Health Economic Evaluation in Japan Lagged behind That in Other Developed Countries? Pharmacoeconomics, 20, 1-7. https://doi.org/10.2165/00019053-200220002-00001

[13] Japanese Ministry of Internal Affairs and Communications (2018) Yearbook of Local Public Enterprise. http://www.soumu.go.jp/english/lpfb/index.html

[14] Coyne, J.S., Richards, M.T., Short, R., Shultz, K., Singh, S.G., et al. (2009) Hospital Cost and Efficiency: Do Hospital Size and Ownership Type Really Matter? Journal of Healthcare Management, 54, 163-174. https://doi.org/10.1097/00115514-200905000-00005

[15] Besstremyannaya, G. (2011) Managerial Performance and Cost Efficiency of Japanese Local Public Hospitals: A Latent Class Stochastic Frontier Model. Health Economics, 20, 19-34. https://doi.org/10.1002/hec.1769

[16] Besstremyannaya, G. (2013) The Impact of Japanese Hospital Financing Reform on Hospital Efficiency: A Difference-Indifference Approach. The Japanese Economic Review, 64, 337-362. https://doi.org/10.1111/j.1468-5876.2012.00585.x 